\title{
Un trazado de acontecimientos: la economía política de la desposesión, el ascenso de Asia oriental y la crisis de la geocultura liberal
}

\author{
Malfred Gerig \\ UNIVERSIDAD SIMÓN BOLÍVAR (USB) \\ malfredgerig7@gmail.com
}

Resumen: Este artículo tiene un doble objetivo. Por un lado, reconstruir los orígenes y dinámica de la economía política global de la coyuntura histórica vigente en la que se combinan: la belle époque financiera del ciclo sistémico de acumulación estadounidense, el desplazamiento del núcleo de la economía global hacia Asia oriental, la disputa por la hegemonía del sistema interestatal devenido global y la disputa por otorgar sentido político a la crisis de la geocultura liberal. A partir de ese diagnóstico, se afirma que el Sistema-mundo moderno se encuentra ante una «crisis de príncipe» en la cual conservadores y radicales se disputan la hegemonía. El trabajo está dividido en tres partes. Primero, se expone la dinámica que conformó la base material de la coyuntura histórica. Segundo, se analizan las respuestas dadas por el giro conservador a la crisis de la geocultura liberal. Por último, se exponen las posibilidades de la política radical emancipatoria de hacer frente a la crisis de la geocultura liberal ante el fracaso del neoconservadurismo.

Palabras claves: Geocultura liberal, Crisis de acumulación, Reproducción ampliada, Neoliberalismo, Política emancipatoria, Sociología histórico-económica.

Abstract: This article has a double objective. On the one hand, to reconstruct the origins and dynamics of the global political economy of the current historical conjuncture in which they combine: the financial belle epoque of the systemic cycle of American accumulation, the displacement of the core of the global economy towards East Asia, the dispute over the hegemony of the interstate system, become global and the dispute over granting political meaning to the crisis of liberal geoculture. From that diagnosis, it is affirmed that the modern world system is facing a "prince crisis» in which conservatives and radicals dispute the hegemony. This work is divided in three parts. In first place, it exposes the dynamics that conformed the material base of the historical conjuncture. Secondly, the answers given by the conservative turn to the crisis of liberal geoculture are analyzed. Finally, it exposes the possibilities of radical emancipatory politics to face the crisis of liberal geoculture after the failure of neoconservatism.

Key words: Liberal geoculture, Crisis of accumulation, Dispossession, Neoliberalism, Emancipatory politics, Historical-economic sociology. 


\section{Introducción: trazar una diagonal para leer la coyuntura histórica}

- Qué define un siglo? Carl Schmitt sentenció que las reglas sobre lo político que regirían el siglo XX se inauguraron cuando Lenin leyó a Clausewitz ${ }^{1}$. Desde la ruptura que señala Schmitt lo político estaría signado por el conflicto antagónico, la organización partidista, la distinción amigo/enemigo y la guerra. Coincidiendo con la periodización, Badiou afirma que «el siglo comienza con la guerra de 1914-1918, guerra que incluye la revolución de octubre de 1917, y termina con el derrumbe de la URSS y el final de la guerra fría. Es el pequeño siglo (75 años), fuertemente unificado» (2005:12). Al periodizar al siglo XX desde esta perspectiva estamos optando por el tiempo de lo político y el acontecimiento, de la puesta en práctica revolucionaria y su fracaso. Así las cosas, el siglo XX fue la centuria marxista y soviética.

¿Y si nos ubicamos en la perspectiva del ser-estructura de la economía-mundo capitalista? ¿Cómo periodizar al siglo XX desde la perspectiva ${ }^{2}$ de la acumulación de capital, los ciclos económicos, el colonialismo y la producción/enajenación de la riqueza? ¿Cómo afrontar el siglo XX como la centuria de Henry Ford y F.D. Roosevelt? Este trabajo sostiene que sólo una perspectiva económica y sistémica puede convertirse en la mediación dialéctica de la perspectiva política-acontecimental y ofrecer una mirada diagonal entre lo económico y lo político. Tomando la dirección de la estructura Arrighi definió al largo siglo XX

Como una unidad constituida por tres fases: (1) la expansión financiera de finales del siglo XIX y principios del siglo XX, en cuyo curso las estructuras del «viejo» régimen de acumulación británico fueron destrozadas y se crearon las del «nuevo» régimen estadounidense; (2) la expansión material de las décadas de 1950 y de 1960, durante las que el dominio del «nuevo» régimen de acumulación estadounidense se tradujo en una expansión de alcance mundial del comercio y de la producción, y (3) la actual expansión financiera, en cuyo despliegue están siendo destrozadas las estructuras del «viejo» régimen estadounidense y se están creando presumiblemente las de un «nuevo» régimen (1999:8)

Este trabajo tiene un objetivo dual. Por un lado, reconstruir los orígenes y dinámica de la economía política global de la coyuntura histórica vigente en la que se combi-

1. «El concepto clásico de «político» establecido en los siglos XVIII y XIX se basaba en el estado entendido según el derecho internacional europeo (...) A partir del siglo XX esta guerra entre estados (...) es dejada de lado y sustituida por una guerra revolucionaria entre "partidos»» (Schmitt, 1985:151.)

2. El cambio de perspectiva de lo político a lo económico nos sitúa en una brecha de paralaje: «un desplazamiento "epistemológico» en el punto de vista del sujeto refleja siempre un desplazamiento "ontológico» en el objeto mismo» (Žižek, 2006:25-26).

3. Braudel descompuso el tiempo histórico en tres niveles: un tiempo geográfico o de larga duración, un tiempo social o de coyuntura y un tiempo individual o del acontecimiento (1976: 17-18-19). Por su parte, Arrighi ha definido al ciclo sistémico de acumulación como la combinación de una fase de expansión material de la economía-mundo 
nan: 1. la belle époque financiera del ciclo sistémico de acumulación estadounidense (Arrighi, 1999: 322; 2007:171), 2. el desplazamiento del núcleo de la economía global a Asia oriental, 3. la disputa por la hegemonía del sistema interestatal devenido global, 4. la querella por otorgar sentido político a la crisis de la geocultura liberal. Por otro lado, el trabajo afirma que el Sistema-mundo Moderno (SMM) se encuentra ante un vacío en el concepto de lo político donde las tres grandes ideologías de la modernidad se disputan una nueva hegemonía histórica ( $C f$. Wallerstein, 2014: cap. 1). En cuanto a lo metodológico, se combina el enfoque narrativo e historiográfico de la economía política de los sistemas-mundo con la teoría política y la sociología histórico-económica para construir una visión holística capaz de abarcar lo económico, lo político y lo social (Wallerstein, 1998:278).

El texto está dividido en tres partes. Primero, se adopta una perspectiva empírica, histórica y diacrónica para exponer la dinámica de la economía política global que origina la coyuntura histórica. Segundo, con perspectiva teórica se analizan las respuestas dadas por el giro conservador a la crisis de la geocultura liberal. Por último, se exponen las posibilidades de la política radical emancipatoria de hacer frente a la crisis de la geocultura liberal ante el fracaso del giro neoconservador.

La operación historizadora que sigue el camino del objeto, a partir de las cuales podemos pensar las formas de lo político más allá del siglo $X X$, pasa por rastrear la dinámica de la transformación ocurrida en las formas de acumulación de capital a escala global que inicia en 1973. El siguiente apartado expone esa transformación desde la dialéctica entre la actuación del Estado capitalista líder y la dinámica de la economía política global.

\section{Economía y política desde 1945: una constelación}

¿Cuál es la situación en la que se encuentra el sistema histórico capitalista al finalizar la Segunda Guerra Mundial? Es pertinente recordar que la diferencia específica de la economía-mundo capitalista es la acumulación incesante de plusvalor. Así como, la centralización del plusvalor desde las zonas periféricas hacia las zonas centrales y desde las clases subalternas a las clases poseedoras ${ }^{4}$. La economía-mundo capitalista siempre ha funcionado en torno a un centro hegemónico capaz tanto de centralizar la riqueza

\footnotetext{
capitalista con una fase de expansión financiera en la que se dibuja un siglo largo donde declina una hegemonía histórica y es sucedida por otra (1999: 18-19). El concepto de coyuntura histórica que se utiliza en este trabajo fusiona los aportes de Braudel y Arrighi para describir la fase por la que atraviese un ciclo sistémico de acumulación. Así, una coyuntura histórica aludirá o a la fase material y consolidación hegemónica de un ciclo sistémico de acumulación, o a la fase financiera, declive hegemónico y disputa por la consecución de un nuevo ciclo sistémico.

4. «El capitalismo implica no sólo la expropiación del plusvalor producido por los trabajadores, sino también una apropiación del excedente de toda la economía-mundo por las áreas centrales» (Wallerstein, 2004:101). Esta tesis de Wallerstein representa una «revolución copernicana» en el marxismo.
} 
producida en la división internacional del trabajo como de otorgar dirección a la acumulación de capital y liderazgo moral al dominio de las clases capitalistas sobre las clases subalternas. El centro hegemónico coordina y da sentido al modo de acumulación y al modo de dominación ${ }^{5}$. Gran Bretaña fue la potencia hegemónica del SMM desde 1815 a 1914. Cuando la hegemonía británica llega a su cenit circa 1870, paradójicamente el imperio de libre comercio (Arrighi, 1999:64) centrado en Londres dependía en mayor grado de sus colonias. La exportación de manufacturas le permitió a Gran Bretaña altos niveles de centralización de divisas extranjeras ávidas de inversiones extraterritoriales, provocando la deslocalización de capitales principalmente hacia Estados Unidos (EUA):

Los títulos detentados por Gran Bretaña sobre los activos y rentas estadounidenses fueron de la mayor importancia en la economía del dominio británico, ya que los Estados Unidos podían proporcionar a Gran Bretaña rápida y eficientemente todos los suministros que esta última precisase para defender su vasto imperio territorial en una guerra global (Arrighi, 1999:324)

$\mathrm{Al}$ iniciarse en 1914 la guerra de treinta años que definiría la hegemonía sobre el sistema, Gran Bretaña necesitó préstamos con los que hacer frente a la falta de insumos, medios de producción y materias primas bélicas. Como consecuencia, en 1918 EUA había mutado de rol en las finanzas internacionales pasando de deudor a principal acreedor. De igual forma la productividad de EUA pasó de estar un 14 por 100 por debajo de Gran Bretaña en 1870 a ser un 20 por 100 superior en 1913 (Panitch y Gindin, 2015: 50). EUA aprovechó el declive británico para iniciar la construcción de un imperio informal (Panitch y Gindin, 2015: 61) capaz de generar un espacio de influencia en América Latina y Canadá en el que penetraran sin obstáculos sus inversiones. En un nivel de similar importancia promovió la internacionalización del dólar estadounidense (USD) a partir de la creación de la Reserva Federal (FED) en 1913 y el surgimiento de Nueva York como núcleo de las altas finanzas globales.

Antes bien, comprender la sucesión hegemónica en el SMM desde una perspectiva centrada exclusivamente en la dinámica del capital confronta dificultades. En este punto es importante recordar la máxima de Braudel según la cual «el capitalismo tan sólo triunfa cuando llega a identificarse con el Estado, cuando es el Estado» (citado en Arrighi, 1999: 25). Para Panitch y Gindin:

Debemos entender la «autonomía relativa» del Estado capitalista: no como autónomo frente a las clases capitalistas o la economía, sino más bien en cuanto a su capacidad para actuar en nombre del sistema como un todo (...) La forma

5. Sobre el concepto de hegemonía véase Anderson (1981: cap. I) y Arrighi (1999: cap. I) 
adoptada internacionalmente por la separación entre lo económico y lo político (...) entre las décadas de 1870 y de 1920 fue incompleta. Los Estados actuaban primordialmente de forma particularista en relación con la acumulación y con el dominio político más allá de sus fronteras (2005:51)

El argumento central aquí es bajo la hegemonía británica el capitalismo no completó el proceso de homogeneización entre Estados y acumulación de capital. El imperialismo de libre comercio británico carecía de una superestructura que organizara al moderno sistema interestatal. Más bien, la organización surgía de facto por el mandato de las altas finanzas centradas en Londres. El proceso de conformación de la triple escisión de la geocultura liberal ${ }^{6}$ no se consolidó hasta 1945 con la hegemonía de EUA. ¿Qué es la triple escisión? Es la forma como la geocultura liberal construyó una ontología social escindiendo lo económico, lo social y lo político. La autonomía relativa de las esferas sociales-vitales en la ontología social liberal está diseñada para que la acumulación de capital sea el significante-amo de la sociedad.

La Segunda Guerra Mundial fue el asalto definitivo entre los candidatos a sustituir a Gran Bretaña en el puesto de mando del SMM y sus resultados configuraron el grado cero geopolítico del mundo bajo la hegemonía de EUA. Al salir derrotados, Alemania y Japón debieron afrontar la destrucción de sus territorios e industrias. Pero la victoria de Gran Bretaña y las fuerzas antifascistas en el resto de Europa se tornó agridulce en tanto su parque industrial quedó igualmente destruido. EUA, por su parte, al no sufrir ataques a su territorio continental no vio afectada su industria, la cual venía perfeccionando la producción intensiva en medios de producción y energía apalancadas en las políticas keynesianas impulsadas por F.D. Roosevelt tras el crac de $1929^{7}$. Tras ser forjada a sangre y fuego por la victoria del ejército rojo sobre la Wehrmacht, con los acuerdos de Yalta (1944) se selló la entrada de la URSS a la política de las grandes potencias ${ }^{8}$.

En 1944 la hegemonía estadounidense en el SMM se había solidificado. Yalta proporcionó la seguridad geopolítica para echar a andar el proyecto del Estado imperial. Las altas finanzas se habían centralizado en EUA bajo un esquema similar al

6. Una geocultura son «un conjunto de ideas, valores y normas que fue ampliamente aceptado en todo el sistema y que a partir de entonces restringió la acción social» (Wallerstein, 2014: 17; Cf. 1996:132-133.)

7. «La guerra reportó, pues, un doble beneficio a los norteamericanos: su economía creció a un ritmo espectacular bajo el estímulo de las adquisiciones militares y el PNB se duplicó entre 1938 y 1945 ; sus tres rivales industriales más importantes -Alemania, Gran Bretaña y Japón- quedaron destrozados y debilitados a raíz del conflicto, de tal manera que Washington se encontraba en posición de reorganizar el universo del capital adaptándolo a sus propias necesidades» (Anderson, 2013: 62).

8. «En términos políticos Yalta fue un acuerdo sobre el statu quo en el cual la Unión Soviética controlaba aproximadamente un tercio del mundo y Estados Unidos el resto» (Wallerstein, 2005:23) 
acogido al finalizar la Primera Guerra Mundial con la intención de apalancar la capacidad productiva y la demanda efectiva9.

El principal problema que afrontaba los EUA era crear demanda efectiva para el inmenso arsenal de mercancías producidos por su economía. La concentración de liquidez se convirtió en un impedimento ya que el resto del mundo no producía suficiente para satisfacer su demanda interna mientras que la industria estadounidense necesitaba una ingente demanda. Fue así como se efectuó un plan consagrado a completar la internacionalización del Estado liberal con el objetivo de lograr la plena internacionalización de la ley del valor. Lo que se publicitó como un acto de benevolencia, consistió en realidad en una nueva expansión territorial ${ }^{10}$ del SMM:

No había precedentes históricos de que una importante potencia apoyara el resurgimiento de sus competidores económicos potenciales como lo hizo Estados Unidos (...) Esto tenía un significado especial: definía el interés nacional estadounidense en términos de la reproducción y de la ampliación del capitalismo global (Panitch y Gindin, 2005:52-53)

Los acuerdos de Bretton Woods se convirtieron en el primer paso dado por EUA para subsanar los atolladeros que conllevaba su recién conseguida hegemonía. En la conferencia se echó abajo el sistema de preferencia imperial británico y EUA reclamó para el USD la posición central de los medios de pagos mundialmente aceptados convirtiendo a la FED en el banco central de la economía global. El control del dinero mundial era un paso clave para institucionalizar la hegemonía de EUA y establecer el marco de regulación que regiría a la economía global en tanto permitió dar curso al capital excedente y resolver los problemas de realización. Desde Bretton Woods el capitalismo es el Estado estadounidense.

En todos los anteriores sistemas monetarios mundiales -sostiene Arrighi-, incluido el británico, los circuitos y las redes de las altas finanzas se habían hallado firmemente en manos de banqueros y financieros privados (...) En el sistema monetario mundial establecido en Bretton Woods, por el contrario, la «producción» de dinero mundial era asumida por una red de organizaciones gubernamentales motivadas básicamente por consideraciones de bienestar, seguridad y poder (1999:334)

Como parte de la misma estrategia surge el Plan Marshall y el Plan Dodge: tratados de asistencia económica que permitieron la reactivación industrial de las zonas afec-

9. «Después de la guerra, el superávit por cuenta corriente era mucho mayor que el superávit comercial» por lo que «Los Estados Unidos disfrutaron de un monopolio virtual sobre la liquidez mundial. En 1947, sus reservas de oro representaban el 70 por 100 del total mundial» (Arrighi, 1999:331).

10. Sobre la relación entre capitalismo y territorialismo véase Arrighi (1994: cap. I y 2007: cap. VIII) y Harvey (2004). 
tadas por la guerra en Europa occidental y Japón respectivamente. El Plan Marshall produjo la demanda efectiva que necesitaba la economía de EUA, pero sobre todo, previno una crisis en la balanza de pagos de las economías europeas que fuese puesto al Fondo Monetario Internacional (FMI) y al Banco Mundial (BM) rápidamente en tensión ${ }^{11}$. El Plan Dodge inició la construcción de la red de producción multiestratificada de Asia oriental centrada en el consumo occidental. No obstante, al notar que las inversiones en infraestructura serían insuficientes para resolver los problemas de demanda, la Guerra de Corea (1950) se convirtió en el suplemento perfecto para invertir en medios de producción de la guerra y contribuir al reciclaje de liquidez ${ }^{12}$. La Guerra de Corea trocó al proyecto de un solo mundo bajo la égida de EUA de F. D. Roosevelt en el pragmático proyecto de contención y tres mundos de la Doctrina Truman (Anderson, 2013:37-38-39). Como resultado Europa occidental y Japón se convirtieron en Estados-protectorados favorecidos por el intercambio político de los EUA $^{13}$ y China fue expulsada de la economía de Asia oriental.

A la solución del problema de liquidez y demanda le acompañaron un conjunto de mecanismos de expansión del sistema de gobernanza interestatal concebidos para proyectar la hegemonía de EUA sobre los asuntos globales: se produce la creación de la Organización de las Naciones Unidas (ONU) en 1945 a partir de los acuerdos de Dumbarton Oaks, se crea la Organización del Tratado del Atlántico Norte (OTAN) en 1949, el Tratado de seguridad entre EUA y Japón y el Tratado Interamericano de asistencia Recíproca (TIAR) en 1947. Como señaló Hopkins: «la hegemonía holandesa posibilitó una economía-mundo capitalista como sistema social histórico; la hegemonía británica clarificó sus fundamentos y se desplazó hacía un dominio global; la hegemonía estadounidense intensificó su alcance, marco y penetración» (citado en Arrighi, 1999: 95).

La geocultura liberal se solidificó como el significante-amo ${ }^{14}$ en el espaciotiempo que se encontraba fuera de la cortina de hierro y la cortina de bambú. Las tasas de crecimiento y beneficio se expandieron hasta convertir al periodo 1944-1973

11. «Gracias al Plan Marshall se canalizaron unos 13.000 millones de dólares que se transformaron en fondos de contrapartida para la recuperación de Europa -controlada por los ejecutivos de las empresas estadounidenses y condicionada a la adquisición de productos norteamericanos-» (Anderson, 2013:65-66)

12. «El rearme masivo que tuvo lugar durante y después de la Guerra de Corea resolvió de una vez por todas los problemas de liquidez de la economía-mundo postbélica. La ayuda militar a los gobiernos extranjeros y los gastos militares directos de los Estados Unidos en el exterior (...) proporcionaron a la economía-mundo toda la liquidez que necesitaba para expandirse» (Arrighi, 1999:357)

13. La noción de intercambio político expresa el intercambio de protección y trato preferencial dado por un agente soberano con capacidad de ejercer violencia legítima a un grupo burgués/comercial con la intención de beneficiarse de su actividad económica (Cf. Schumpeter, 1868:189; Arrighi, 1999: 146)

14. «¿Qué es entonces el Significante-Amo? Imaginemos una confusa situación de desintegración social en la cual el poder cohesivo de la ideología pierda su eficacia: en una situación así, el Amo es aquel que inventa un nuevo significante, el famoso "quilting point» que vuelve a estabilizar la situación y la hace comprensible» (Žižek, 2006: 58-59). 
en la edad de oro del capitalismo ${ }^{15}$ : un ciclo de expansión en la producción industrial de mercancías, los niveles de vida, consumo, educación y la interconexión mundial. En suma:

Podemos decir que en los años comprendidos entre 1945 y 1970 el liberalismo tuvo una segunda apoteosis. Si en los decenios anteriores a 1914 aparentemente había triunfado en Europa, entre 1945 y 1970 dio la impresión de triunfar en el mundo entero (Wallerstein, 1996:158)

La superioridad de EUA y del liberalismo como geocultura no durarían para siempre. A mediados de la década de 1960 las reservas de oro de EUA empezaron a disminuir a límites que no soportarían al patrón oro-dólar. La delantera tomada por el capital estadounidense al iniciarse la posguerra permitió que la Corporación Verticalmente Integrada (CVI) penetrara fácilmente en el mercado europeo y japonés. No obstante, en la década de 1970 empresas alemanas y japonesas presentaron un crecimiento en sus niveles de productividad aumentando sus tasas de beneficio.

Desde allí la disputa intercapitalista se daría en el plano de la inversión, por lo que la protección de la CVI estadounidense implicaba redireccionar el rumbo de la economía global. Pese a que la inversión de EUA aumentó considerablemente no logró desplazar a la inversión directa no-estadounidense. Siguiendo a Contreras Natera:

Los acuerdos del sistema Bretton Woods (...) estaba colapsado como consecuencia de presiones especulativas en los mercados financieros, forzando al gobierno de los Estados Unidos a declarar al dólar oficialmente inconvertible en oro y, dos años después, a abandonar las tasas fijas de cambio. Por el otro, entre 1964 y 1972, los Estados Unidos había realizado un poderoso despliegue tecnológico y militar con el objeto de derrotar militar y políticamente un movimiento nacionalista y revolucionario en Vietnam. El resultado final fue una humillante derrota militar (2011:210-211)

Paradójicamente, el trastocamiento del patrón oro-dólar a un patrón dólar a secas no debilitó la posición de Washington como agente que controla el dinero mundial. «Lo que se estaba produciendo» según Panitch y Gindin «era una transición desde los tipos de cambio fijos dirigidos a promover la reconstrucción capitalista bajo el Plan Marshall (...) al establecimiento de la infraestructura legal, institucional y de

15. «Un periodo durante el cual el capital excedente se reinvirtió de nuevo en el comercio y la producción de mercancías a una escala lo suficientemente amplia como para crear las condiciones de una cooperación y una división del trabajo renovadas en el interior de/entre las organizaciones gubernamentales y empresariales de la economía mundo capitalista» (Arrighi, 1999:358) 
mercado que sustentaría a la globalización capitalista en medio de tipos de cambio flotantes» (2015:220).

El estancamiento de la productividad de la CVI permitió que los salarios reales se colocaran por encima de la productividad del trabajo produciendo una caída en la tasa de beneficios. Aunado a ello, en 1973 la Organización de Países Exportadores de Petróleo (OPEP) decidió realizar un embargo como parte de la guerra de Yom Kipur contra de los aliados de Israel produciendo un aumento de los precios de las manufacturas tanto en los países centrales como periféricos ${ }^{16}$. Para los países productores de petróleo representó un aumento de los excedentes que se tradujeron en importaciones de bienes de consumo de los países del Norte, fondos de inversión en EUA y Alemania, y una renta capaz de librarlos de las oscilaciones del USD ${ }^{17}$. Para el Sur global en general representó una reducción drástica de las exportaciones que condujo a problemas en la balanza de pagos.

Los excedentes que se encontraban en la banca de inversión necesitaban retornar al proceso de valorización. Los países que requerían préstamos con tasas de interés atractivas, especialmente en el Tercer Mundo, se convirtieron en el destino del excedente. «Los bancos de inversión de Nueva York -comenta Arrighi- siempre habían mantenido un elevado nivel de actividad en el plano internacional pero después de 1973 está actividad se intensificó notablemente, aunque ahora estaba mucho más centrada el préstamo de capital a gobiernos extranjeros» (1999:35).

Los tipos de cambio flotantes se convirtieron en dispositivos de regulación de las economías del Tercer Mundo, al tiempo que una apuesta del Estado imperial por mantener el control de la CVI sobre el mercado mundial (Wade, 2006). No obstante, la desregulación ocasionó que la liquidez no fuese utilizada en inversiones para la producción de mercancías, lo que hipotéticamente provocaría una nueva expansión material de la economía mundial, al contrario, «La mayor parte de esa liquidez se convirtió en petrodólares y en eurodólares, que se multiplicaban a sí mismos mediante los mecanismos interbancarios de creación de dinero (Arrighi, 1999:377). Así, los regímenes cambiarios basados en la fluctuación del tipo de cambio produjeron la multiplicación del estancamiento económico y la inflación.

16. La inflación anual pasó de ser 1.5 por 100 en EUA y 4 por 100 en la Unión Europea en 1965 a ser 11 por 100 y 13.6 por 100 en 174 respectivamente. (Banco Mundial, 2019)

17. La renta del petróleo como porcentaje del PIB de Arabia Saudita pasó del 29.3 por 100 en 1970 a 69.9 por 100 en 1974; en Irán del 13.5 por 100 al 49.3 por 100 en el mismo periodo; en Irak del 18.3 por 100 al 64.7 por 100 y en Venezuela del 6.9 por 100 al 34.2 por 100. Para 1982 en ninguno de los países referidos las rentas del petróleo pasaban el 37 por 100 como porcentaje del PIB. (Banco Mundial, 2019). 


\section{La belle époque de la hegemonía estadounidense (1982-2007)}

La caída de los beneficios no tardó en generar respuestas político-espirituales en los países centrales del SMM. El neoliberalismo fue ganando cada vez más adeptos mientras que el keynesianismo, al mostrarse incapaz de hacer frente a la estanflación, entró en decadencia como explicación de la economía política del capitalismo.

Cuando la economía-mundo capitalista se dirigía hacia la financiarización, desregulación y caída de los beneficios el Estado estadounidense volvió a erigirse como actor clave en la conducción de la economía global. La puerta de entrada de la restauración conservadora fue el shock de Volcker ${ }^{18}$, que consistió tanto en el aumento de los tipos de interés nominal como en propiciar la desregulación financiera, libertad a los flujos de capitales, los derivados financieros y el endeudamiento público exponencial. Las medidas buscaban la externalización al Sur global de capitales poco competitivos. Se trataba de reconducir el papel del capital estadounidense en la economía global sin tener que pasar la producción:

A partir de entonces, el capitalismo funcionaría bajo «una nueva forma de regulación social» que prometía no sólo un resurgimiento de la base productiva del dominio estadounidense, sino un modelo para restaurar las condiciones de la obtención de beneficios en otros países desarrollados (...) la «interpenetración mutua» entre Wall Street y el Estado fortaleció los recursos imperiales de Estados Unidos (Panitch y Gindin, 2005:56-57)

El aumento de los tipos de interés no representó buenas noticias para los países que habían obtenido préstamos a bajo costo en la década de 1970. Inmediatamente surgió la crisis de deuda, especialmente en América Latina, como expresión de las relaciones de dependencia con EUA ${ }^{19}$. Para América Latina los Programas de Ajuste Estructural (PAE) significaron el vehículo de entrada de una nueva ofensiva de desposesión que buscaba acabar con el proteccionismo selectivo implementado durante la era de la industrialización por sustitución de importaciones a favor de la industrialización para la exportación que preconizaban las, reactualizadas bajo cuño neoliberal, ventajas comparativas ricardianas. Incapaz de afrontar el problema de la crisis de acumu-

18. «El tipo de interés real que a menudo había sido negativo durante la cresta inflacionaria de dos dígitos de la década de 1970 se tornó positivo por orden de la Reserva Federal (...) El tipo de interés nominal subió de un día para otro y, tras las oscilaciones benignas, en julio de 1981 se mantuvo en torno al 20 por 100 (...) En opinión de Volcker, esta era la única salida a la incómoda crisis de estanflación que había caracterizado a Estados Unidos y a gran parte de la economía global a lo largo de toda la década de 1970» (Harvey, 2007:30).

19. El volumen de deuda externa como porcentaje de las exportaciones paso de ser en 1976 de 299,5 por 100 en Brasil, 202,5 por 100 en Argentina y 48,1 por 100 en Venezuela y 244,5 por 100 para México en 1979, a 436,2 por 100 en Brasil, 595,9 por 100 en Argentina, 305, 2 por 100 en Venezuela y 356.7 en México en 1986. (Banco Mundial, 2019) 
lación por la vía de la reproducción ampliada ${ }^{20}$ el capital acudía a la lucha de clases en busca del plusvalor.

Con la contrarrevolución monetarista iniciada en 1982 la economía de EUA perdió la hegemonía en el sector industrial que había caracterizado al periodo 1945$1973^{21}$. Para mantener la competitividad, las CVI optaron por deslocalizar la producción y así gozar de los beneficios que otorgaba la fuerza de trabajo barata producto del proceso de desruralización del mundo (Wallerstein, 1996:4). Como señala Harvey: «la economía estadounidense se estaba convirtiendo en una economía rentista en relación con el resto del mundo y una economía de servicios en el propio país» (2004:64). Así, quedaba en evidencia una de las pautas recurrentes durante las expansiones financieras de los ciclos sistémicos de acumulación: la externalización de la crisis. Esta, le permite a la potencia hegemónica ganar tiempo, pero tras dos décadas «tienden a desestabilizar el orden existente» en tanto «desvían sistemáticamente el poder de compra de la inversión creadora de demanda de mercancías (incluida la fuerza de trabajo) hacia el atesoramiento y la especulación, exacerbando así los problemas de realización» (Arrighi, 2007: 172).

Las clases capitalistas desarrollaron dos tipos de respuesta a la crisis iniciada en 1973 que forjaron los fundamentos materiales de la coyuntura histórica vigente. Por una parte, los capitales incapaces de competir en las zonas centrales optaron por lo que Harvey denominó soluciones espacio-temporal22: buscar territorios donde competir con menos controles, menores tasas de interés, y, sobre todo, poder entrar en el proceso de valorización a partir de una menor acumulación cuantitativa cuya condición de posibilidad es la menor acumulación orgánica de los capitales nacionales periféricos.

Asia oriental fue la región que se benefició en mayor medida del proceso de deslocalización. En primer lugar, Japón nucleó a la cadena de valor de Asia oriental que tenía como destino el consumo del Norte global. Posteriormente los Tigres asiá-

20. Sobre la reproducción ampliada véase Luxemburgo (1967: cap. VI); Harvey (2004).

21. El déficit por cuenta corriente expresa el deterioro de la situación competitiva de las agencias de acumulación de capital de EUA. Desde 1970 EUA arrastra un déficit crónico en su cuenta corriente como porcentaje del PIB, en 1973 contaba con un superávit de 0,5 por 100, en 1987 el déficit llegó al 3,3 por 100 y pese a recuperarse en 1991 consiguiendo un superávit de 0,04 por 100, el déficit llegó 5,8 por 100 en 2006 y ronda el 2,3 por 100 del PIB en 2018. Por su parte, el superávit de China y Alemania era para 2006 de 8,4 por 100 y 5,7 por 100 del PIB y 0.3 por 100 y 7.2 por 100 para 2018 respectivamente (Banco Mundial, 2019).

22. «La «solución» espacio temporal (...) es una metáfora de un tipo particular de resolución de las crisis capitalistas mediante la demora temporal y la expansión geográfica (...) La producción del espacio, la organización de divisiones territoriales del trabajo totalmente nuevas, el acceso a complejos de recurso inéditos y más baratos, la promoción de nuevas regiones como espacios dinámicos de acumulación de capital y la penetración en formaciones sociales preexistentes de las relaciones sociales y de los dispositivos institucionales capitalistas» (Harvey, 2004:97) 
ticos (Corea del Sur, Taiwán, Hong Kong y Singapur) se convirtieron en proveedores de gama media de Japón. A esto le acaeció el recentramiento de la economía China, que repitiendo el modelo de desarrollo de los Tigres asiáticos, logró transformar la división del trabajo de la región centrada en Japón en una red de producción sinocéntrica (Ho-fung Hung, 2010; Arrighi, 2007: cap. XI y XII).

Por otra parte, la crisis de acumulación fue afrontada por las clases capitalistas con lo que Harvey ha denominado acumulación por desposesión. Para Harvey el capitalismo necesita, especialmente en épocas de crisis, un afuera del cual nutrirse. Las formas de colonización/ocupación forzada de territorios no dominados por la lógica del capital, la proletarización de sectores campesinos que se mantenían reacios a la agricultura extensiva privada, los mecanismos de reciclaje de la deuda, el pillaje de riqueza desde el centro hasta la periferia, las privatizaciones, las patentes y regalías, no son formas de apropiación/enajenación de la riqueza que han quedado en una etapa primitiva del capitalismo. Al contrario, siguen vigentes y son necesarias para que la rueda de la acumulación siga girando. En sus palabras:

La acumulación por desposesión se agudizó cada vez más desde 1973, en parte para intentar compensar los problemas crónicos de sobreacumulación surgidos en la reproducción ampliada. El mecanismo principal de este proceso fue la financiarización y la puesta en pie, principalmente por Estados Unidos, de un sistema financiero internacional que pudiera, de vez en cuando, emprender acometidas más o menos severas de devaluación y acumulación por desposesión contra ciertos sectores y hasta territorios enteros (Harvey, 2004:124-125)

Por consiguiente, la problemática central de la economía-mundo capitalista a partir de la década de 1970 es la incapacidad para la reproducción ampliada de capital. Para que la reproducción ampliada tenga lugar un porcentaje del producto tiene que invertirse en nuevos medios de producción posibilitando la capitalización de parte de la plusvalía en un nuevo proceso de producción ${ }^{23}$.

Las soluciones espacio-temporales le permitieron a EUA contener los efectos de la crisis de reproducción ampliada y el declive de su hegemonía sobre el SMM durante la belle époque estadounidense (Arrighi, 2007: 159). Este período de «recuperación» se prolongó desde el inicio de la contrarrevolución monetarista en 1982 hasta el estallido de la Gran Recesión en 2007 (Cf. Panitch y Gindin, 2015: 280). Con la crisis de 2007 podemos sostener que la hegemonía de EUA en la economía global 
ha llegado a sus límites inherentes, iniciándose un periodo de disputa por la aparición de un nuevo Estado hegemónico para el SMM en sus componentes centrales: el moderno sistema interestatal devenido global, la economía-mundo capitalista y su respectiva geocultura.

Las soluciones espacio-temporales y la acumulación por desposesión han configurado un principio de realidad global radicalmente distinto al que imperó durante los gloriosos treinta. La superpoblación, las ciudades miserias, la pobreza, el hambre, la desposesión, la crisis ambiental, las migraciones, la violencia social, la exclusión y el racismo, se han convertido en la demostración de la incapacidad del capital para crear riqueza sin destruir vida, naturaleza y medios de producción en el proceso. La apuesta del neoliberalismo por la radicalización de la mercantilización y privatización del mundo tiene como resultado la mayor centralización de la riqueza en la historia entre regiones, Estados y clases sumergiéndonos en la era de la desigualdad y la desposesión.

Argüimos que a partir de 1968/1973 el capitalismo afronta una crisis en su agente político cohesionador: la geocultura liberal. Las soluciones espacio-temporales y la acumulación por desposesión han dinamitado al reformismo racional. Las políticas de ajuste estructural conducidas por la tecnocracia neoliberal han develado al liberalismo como un régimen de gobierno profundamente antidemocrático. En el siguiente apartado se analiza cómo fue la respuesta de la derecha del espectro político a la crisis de la geocultura liberal que comenzó en 1968.

\section{Control de daños o el intento del giro conservador}

Friedrich Hayek y Leo Strauss ${ }^{24}$, dos de los principales autores del tándem neoliberal-neoconservador ${ }^{25}$, coinciden en su actitud nostálgica con respecto a un liberalismo puro que en sus consideraciones se ha perdido en los últimos dos siglos. Hayek sostiene:

Entenderé por liberalismo la concepción de un orden político deseable que en el comienzo se desarrollo en Inglaterra, a partir de la época de los Oíd Whigs al término del siglo XVII, hasta aquella de Gladstone a fines del XIX. David Hume, Adam Smith, Edmund Burke, T. B. Macaulay y Lord Acton pueden ser considerados como sus representantes típicos (...) Este liberalismo debe ser distinguido

24. Sobre Hayek véase Contreras Natera (2015: cap. I); sobre Strauss véase Contreras Natera (2011: 19).

25. La relación entre neoconservadurismo y neoliberalismo que aquí se expresa se refiere más que a una afinidad genealógica, a una afinidad programática ante los efectos de la Revolución Mundial de 1968. Más que establecer una afinidad teórica entre neoliberalismo y neoconservadurismo establecemos una afinidad política y espiritual. Para una genealogía del neoliberalismo véase Mirowski y Plehwe (2009), Contreras (2015) y Harvey (2007). 
claramente de otro, originalmente de tradición continental europea, también llamado "liberalismo», del cual es un descendiente directo el que actualmente reclama este nombre en los Estados Unidos (...) Esta es la tradición de Voltaire, Rousseau, Condorcet y de la Revolución Francesa, que se convirtió en antecesora del socialismo moderno (1996:179-180)

Por su parte, Strauss (2007:10) opina que «el conservadurismo de nuestra época es idéntico al liberalismo originario (...) Se podría ir más allá y decir que gran parte de lo que hoy se entiende por conservadurismo en última instancia comparte una raíz con el liberalismo».

Las convergencias analíticas y programáticas de neoliberales y neoconservadores en torno a la pérdida de cualidades del proyecto liberal genuino al igual que el rechazo a la Revolución Francesa como acontecimiento-verdad nos hablan de un proyecto conservador de nuevo cuño que procura reabrir las disputas que la geocultura liberal había contenido desde 1848 con la intención de conseguir una nueva clausura que contenga a las fuerzas sociales emancipatorias desatadas en la década de 1960 y 1970.

La Revolución Mundial de 1968 (Wallerstein, 2007:94) se convirtió en un punto de quiebre del SMM:

Los sucesos que recorrieron desde Vietnam a Camboya, pasando por la Primavera de Praga en Checoslovaquia, la lucha por los derechos civiles de los afroamericanos, el asesinato de Malcolm X y de Martin Luther King en EEUU, el Mayo francés, la matanza de Tlatelolco en México, el estallido en la Universidad de Columbia, la Revolución Cultural de Mao (Gerig, 2018: 270)

La multiplicidad ideológica y geográfica del acontecimiento 1968 no tardó en despertar interpretaciones entre la intelectualidad orgánica del sistema. El texto clave en ese sentido es Crisis de la democracia (1975), un informe redactado por Crozier, Huntington y Watanuki a pedido de la Comisión Trilateral que se proponía indagar en el estado de las democracias en los polos industriales del mundo para hacerle frente al pesimismo que la época inducía en lo económico y lo político. El informe concluía que entrabamos en una época cualitativamente distinta a la posguerra caracterizada por la democracia anómala, la incapacidad para sumar población a la clase media, el descrédito sobre la participación política, la aparición de nuevos valores sociales, el declive del poder económico y militar de EUA y el estancamiento económico prolongado (Crozier, Huntington y Watanuki, 1975: 157-158). La crisis política-cultural iniciada en 1968 y la crisis de acumulación de capital de 1970 se habían convertido en un llamado a la acción para las fuerzas conservadoras quienes se sumaban a la deslegitimación de la geocultura liberal. La geocultura liberal recibió dos golpes en estas 
décadas. El primero fue propiciado por parte de la Nueva izquierda, y el segundo, por parte de la Nueva derecha, neoliberal en lo económico y neoconservadora en lo político. Para los neoconservadores había «Una inflación de expectativas y una proliferación de demandas que hacen explotar drásticamente las actividades del Estado (...) El deterioro del Estado benefactor ha distorsionado la naturaleza humana y ha convertido a los ciudadanos en clientes» (Contreras Natera, 2011:218)

Para el giro conservador el reformismo racional se había tornado peligroso ya que las demandas por transformaciones sociales demostraban que la participación política concluía en una superación de la capacidad mediadora del Estado ocasionando una crisis de gobernanza. La solución neoliberal pasaba por un movimiento de fetichización de lo político que trasladara las demandas políticas dirigidas al Estado hacia el consumo/mercado. En el marco del giro hacia la financiarización, los neoliberales y neoconservadores buscaban generar confianza ante la autoridad, inserción económica, nuevos valores, participación social e incremento de la riqueza, al tiempo que desalojaban del Estado la lógica del poder e instalaban la lógica del beneficio y la tradición. Se buscaba reducir la plenitud social a la esfera del mercado propiciando la afinidad entre la utopía de la filosofía social neoliberal y las prácticas desregularizadoras de las altas finanzas.

La idealización del mercado capitalista que realizan los neoliberales los lleva a concebir que su axiomática principal, a saber, el orden espontáneo sin ningún propósito más que el beneficio individual, puede ser trasladado ad hoc a cualquier esfera de la vida social. La crítica neoliberal cree que el Estado liberal no solo distorsiona a la democracia al tratar de otorgar por vía política beneficios que solo se pueden y deben conseguir individualmente en el mercado, sino que con ello distorsiona también al mercado. Así las cosas, «el mercado es societas perfecta que nunca tiene ninguna culpa, pero frente a la cual todos son culpables» (Contreras, 2015: 72).

El intento de otorgar al SMM un nuevo significante-amo por parte del giro conservador buscaba una transformación en tres aspectos. En primer lugar, transformar la semántica sobre lo político. Para el giro conservador la asíntota que vincula a lo social con lo político se había juntado en demasía durante la Revolución Mundial de 1968 por lo que debía ponerse en marcha un movimiento de despolitización de la sociedad y el mercado.

En segundo lugar, el proceso de despolitización se suplementa en una ofensiva que procuraba volcar todas las fuerzas políticas y sociales al restablecimiento de los beneficios de las clases capitalistas. En ese sentido Harvey ha definido al neoliberalismo como una ofensiva de clase: «La neoliberalización no ha sido muy efectiva a la hora de revitalizar la acumulación global de capital pero ha logrado de manera muy satisfactoria restaurar o (...) crear el poder de una elite económica» (2004:24-25). La 
utopía neoliberal buscaba la subsunción de la totalidad de la vida a la axiomática del mercado capitalista occidental en su fase de financiarización extrema llevando al paroxismo el fetichismo de la mercancía expresado por Marx según el cual en el capitalismo los seres humanos se relacionan socialmente como cosas.

En tercer lugar, el proyecto neoconservador se proponía que EUA continuará siendo la potencia hegemónica del SMM. «El neoconservadurismo (...) debía interpretarse como un intento tardío de responder al declive de la hegemonía de los Estados Unidos» (Contreras Natera, 2011:213). La relación entre régimen de acumulación y marco de regulación es puesta sobre la mesa para solucionar el desgarramiento que se había producido entre cultura y sociedad:

Los neoconservadores estigmatizan la cultura moderna como irracional en tanto esta ya no produce los principios axiológicos y las motivaciones sociopsicológicas requeridos por el capitalismo tardío (...) El propósito del diagnóstico sobre la cultura adversaria es erradicar y estigmatizar el legado de los años sesenta (Contreras Natera, 2011:204-206-207)

Las fuerzas conservadoras se proponían realizar un doble movimiento profiláctico. Ante lo que creían que eran los excesos de los acontecimientos de 1968 argüían que estos demostraron que el reformismo racional había perdido la capacidad hegemónica conllevando a una crisis de gobernabilidad. Urgía entonces profundizar la escisión de lo político y los social para reducir intensidad a las democracias otorgándoles cada vez más responsabilidad en la toma de decisiones a los tecnócratas orientados a gobernar a favor de las altas finanzas.

El intento de solución a la crisis de la geocultura liberal por parte de las fuerzas conservadoras pasaba por despolitizar lo social y lo económico, transitar hacia sistemas de gobernanza elitistas y tecnócratas, apalancar la acumulación de capital en las finanzas sin pasar por lo productivo y mantener el control del Atlántico Norte sobre la economía-mundo capitalista. Esto explica porque dos figuras distantes entre sí, sin afinidad teórica aparente, como Strauss y Hayek conminaron a retornar a un supuesto liberalismo primitivo que en la actualidad tomaba el rostro de un nuevo conservadurismo.

Pese a que neoliberales y neoconservadores contrastan en múltiples cuestiones de índole teórica y moral, ambos movimientos se convirtieron en la respuesta político-espiritual de las clases capitalistas a la Revolución Mundial de 1968 y la crisis de la geocultura liberal. El tándem neoliberal-neoconservador ejerció como suplemento de la crisis de la geocultura liberal durante la belle époque (1982-2007) de la hegemonía estadounidense sobre el SMM. Sin embargo, tras la Guerra de Irak y la Gran Recesión el giro conservador se ha mostrado infructuoso para reconducir el sentido del capitalismo histórico. De esta manera, se ha reabierto el campo político global a 
la disputa ideológica. El populismo como lógica de construcción de lo político ( $C f$. Laclau, 2005) se está convirtiendo en el agente movilizador de una época caracterizada por la desigualdad social, la reemergencia de los nacionalismos identitarios, las nuevas modalidades de organización y el cinismo político en la cual el neoconservadurismo necesita tomar prestadas la retórica antisistema de la izquierda para sobrevivir a sus propios estragos.

\section{La política radical emancipatoria}

¿Cuál es la posición de los movimientos antisistémicos y emancipatorios ante esta constelación política? El espíritu de la época sigue siendo profundamente «fukuyamiano» (Žižek 2011: 431), mientras que el espíritu de las fuerzas de izquierda sigue siendo «lyotardsiano» en tanto que se encuentra obsesionado por la crítica, la deconstrucción y la sustracción, sin ofrecer alternativas programáticas para la gestión de la sociedad y la economía.

Fue Lyotard quien sentenció en La condición postmoderna (1987) que la época se caracterizaba por el fin de los meta-relatos. Nos encontrábamos entonces en un mundo diseminado, disperso, desestructurado, azaroso y complejo. La utopía absoluta de las clases poseedoras coincidía con el fin de cualquier otra utopía. Los militantes de la metafísica de las descripciones (Vattimo y Zabala, 2012:26) se declararon victoriosos y en ofensiva.

Ahora bien, como ha recalcado Badiou, «la apología moderna de la «complejidad» del mundo (...) no es en realidad sino un deseo generalizado de atonalidad» (Citado en Žižek, 2011:37). El deseo de dispersión es la expresión sintomática de la crisis del significante-amo que rigió al SMM tras 1848: la geocultura liberal. Posterior al torque del espectro político hacia la derecha en la década de 1980, y la subsunción/ neutralización del liberalismo por parte del conservadurismo, debemos preguntarnos por la dimensión forcluida en estos desplazamientos. ¿Qué es aquello que ha sido desplazado/expulsado y sin lo cual el mundo parece ser una dispersión de mundos sin punto de sostén ni conexión? La respuesta es la política radical emancipatoria.

La disolución del significante-amo es en sí despolitizador: «la suspensión del Significante-Amo deja como única instancia de interpelación ideológica el «innombrable» abismo del goce: el imperativo último que regula nuestras vidas en la 'posmodernidad" es «igoza!»» (Žižek, 2011:37). El diseño de un mundo atonal es funcional a las formas multiculturales de reconocimiento, la dispersión individual, el híper-consumo, el hedonismo, el goce como motivación, la exclusión, la violencia, las religiones identitarios, es decir, un mundo que en la medida que fue diseñado por la acumulación de capital resiste a cualquier argumento moral universal en su contra. La cuestión central es que la acumulación de capital sigue siendo el punto de almoha- 
dillado que mantiene conectado al mundo atonal. El goce del acceso a la mercancía en el Norte global es el trauma del trabajo capitalista en el Sur.

La crisis del significante-amo ha dejado abierto la disputa entre los distintos significantes particulares por colonizar al Amo. En otras palabras: está abierta la disputa por inventar un nuevo significante-amo. Las fuerzas conservadoras fueron los primeros en intentar otorgar al SMM un nuevo significante-amo que restituya la eficacia del anterior sin modificar el punto de sostén del sistema: la acumulación de capital. Para Wallerstein: «En la medida en que hoy ya no existe una fe generalizada en el reformismo racional por la vía de la acción estatal, el liberalismo ha perdido su principal defensa político-cultural contra las clases peligrosas» (1996:263-266).

El intento neoliberal-neoconservador de acentuar los rasgos antidemocráticos de la geocultura liberal ha sido infructuoso. Los Estados son incapaces de conservar lo político para sí cual Leviatán, y este es el gran legado del marxismo para el futuro, a saber, haber alojado de nuevo lo político en lo social. Desde la disolución de la URSS una multitud de fuerzas políticas han aparecido en el SMM, con especial ebullición en América Latina. La politización como manera de luchar contra las efectuaciones de la acumulación de plusvalor es cada vez más asumida por los excluidos del mundo. El poder circula cada vez más por lo social, dejando desestructuradas a las políticas del orden y el Estado. Estamos ante la invención tanto de un nuevo príncipe como de un nuevo leviatán, es decir, el fin de la forma partido y la forma Estado tal y como nos la legó el siglo XX.

La disputa por los conceptos adecuados es un conflicto de interpretaciones sobre la incapacidad del legado hobbesiano y su física social para resolver la problemática del mundo contemporáneo. La crisis de la geocultura liberal es la crisis de la política entendida como dispositivo para la conquista del poder del Estado. En cambio, el proyecto de socialización de lo político marxiano sigue abierto como posibilidad acontecimental.

Ante la tentación de recurrir a formas atonales de subsistencia que aspiren al simple reconocimiento nominal es necesario establecer una transición al acto: el tipo de vinculación colectiva, que ha sido llamada la hipótesis comunista (Badiou, 2008), donde el plano de disputa es la universalidad: «es esta misma universalidad vacía la que es una necesidad de la no coincidencia radical del particular consigo mismo» (Žižek, 2006:66).

Esa universalidad vacía y excluida es la política radical emancipatoria. La universalidad que dada su apetencia por el antagonismo no se fija en la sustancialidad de una parte con respecto a sí misma (políticas de la identidad), sino en la necesidad de atravesar todas las partes por una misma universalidad donde las particularidades se potencien (ontologías plurales). La tarea de los movimientos emancipatorios es obrar 
en la producción de esa verdad colectiva capaz de reinventar una forma de pensar, decir y sentir a través lo político que ponga en acto la universalidad concreta en lo social.

Ahora bien, el conservadurismo parece haber entendido que la lógica populista de construcción del antagonismo se inserta perfectamente en el mundo atonal. Movimientos conservadores de diversa índole gobiernan hoy de Brasilia a Nueva Delhi, de Moscú a El Cairo, de Ankara a Budapest, de Washington a Varsovia. En lo político el siglo XIX fue el siglo del liberalismo, el XX el del marxismo, ¿será el siglo XXI el siglo conservador? En lo económico, sin embargo, el siglo XX fue el siglo liberal y el XXI será el siglo marxista con su específico matiz taoísta. La paradoja que tenemos ante nosotros es que los conservadores son la fuerza política que está siendo capaz de movilizar a partir del antagonismo social. Siendo el antagonismo social el único universal concreto, quien lo colonice forjará una nueva geocultura para el SMM.

\section{Conclusión: China y la nueva geocultura}

El proceso histórico-económico de mayor envergadura que presenciará el siglo XXI es la reorientación del centro de la economía global hacia Asia oriental. Un desplazamiento de esas dimensiones suele imbricar tres fenómenos interdependientes, pero semi-autónomos: «la intensificación de la competencia interestatal e interempresarial; la escalada de conflictos sociales; y el surgimiento intersticial de nuevas configuraciones de poder» (Arrighi y Silver, 2001: 36). En la actualidad China es el núcleo irradiador de esas tres dinámicas a nivel global. Beneficiada por la deslocalización que ocasionó la belle époque financiera del ciclo sistémico de acumulación estadounidense, la República Popular fue capaz de convertir, a partir de su milenaria historia económica, a la red de producción multiestratificada centrada en Japón en una red de producción sinocéntrica dependiente del consumo del Norte global. Pero una vez rebasado los límites inherentes de la industrialización para la exportación China ha emprendido un recentramiento titánico de su modelo de desarrollo para reducir la dependencia con el consumo occidental al fomentar el consumo tanto internamente como en el Sur Global, aumentar la productividad del trabajo vía uso intensivo en tecnologías y reducir la cantidad de combustibles fósiles utilizado en el proceso de producción. El resultado del reequilibrio del modelo de desarrollo chino será un componente central en la dinámica del SMM en el siglo XXI.

No es extraño que liberales, conservadores y radicales hayan querido apropiarse analíticamente del despegue económico chino. Mientras que Arrighi vio en el recentramiento de China la posibilidad para la construcción de una sociedad mundial de mercado como la presagiara Adam Smith (Arrighi, 2007: 403), Connery (2019) cree 
que el éxito chino se ha sustentado en el uso por debajo de la mesa de las máximas neoliberales como las preconizara Ronald Coase.

Ahora bien, si Hegel creía que el espíritu de la historia iba de Oriente a Occidente, el espíritu de lo político va en dirección contraria. Parte de la provinciana Europa y su despliegue es la historia de la universalización de sus conceptos y sus lógicas. Inicia con las consecuencias no esperada de la emancipación colonial en América como respuesta a la Revolución Francesa. Se consuma teóricamente con la llegada del comunismo a Oriente en 1949 con la Revolución China. El vacío del concepto de lo político que describe este artículo será llenado por la nueva configuración supra-estructural que nazca de las nuevas relaciones de poder global que tiene que forjar el Estado chino en tanto que aspirante central a la hegemonía sobre el SMM. Paradójicamente, es en Asia oriental donde las máximas de la geocultura liberal tienen todavía relevancia, pero sirviendo al socialismo con características chinas.

\section{Bibliografía}

ANDERSON, P. (1981) Las antinomias de Antonio Gramsci. Estado y revolución en occidente, Barcelona: Fontamara.

ANDERSON, P. (2013) Imperium et Consilium. La política exterior norteamericana y sus teóricos, Madrid: Akal.

ARRIGHI, G. (1999) El largo siglo XX. Dinero y poder en los orígenes de nuestra época, Madrid: Akal.

ARRIGHI, G. SILVER B. J. (2001) Caos y orden en el sistema-mundo moderno, Madrid: Akal.

ARRIGHI, G. (2007) Adam Smith en Pekín. Orígenes y fundamentos del siglo XXI, Madrid: Akal.

BANCO MUNDIAL (2019) Banco Mundial Datos. https://datos.bancomundial.org/ BADIOU, A. (2005) El siglo, Buenos Aires: Manantial.

BADIOU, A. (2008) «La hipótesis comunista», New Left Review, 49, (mar-abr 2008), pp. 27-38. https://newleftreview.es/issues/49/articles/alain-badiou-la-hipotesiscomunista.pdf

BRAUDEL, F. (1976) El Mediterráneo y el mundo mediterráneo en la época de Felipe II, Tomo I, México: Fondo de Cultura Económica.

CONNERY, C. (2019) «Ronald Coase en Pekín», New Left Review, 115, (mar-abr 2019), pp. 31-61. https://newleftreview.es/issues/115/articles/ronald-coase-enpeki-n.pdf

CONTRERAS NATERA, M. A. (2011) Una geopolítica del espíritu. Leo Strauss: la filosofía política como retorno y el imperialismo estadounidense, Caracas: Fundación Celarg. 
CONTRERAS NATERA, M. A. (2014) Otro modo del ser o más allá del euroccidentalismo, Caracas: Fundación Celarg.

CONTRERAS NATERA, M. A. (2015) Crítica a la razón neoliberal. Del neoliberalismo al posneoliberalismo, México: Akal.

CROZIER, M. J., HUNTINGTON, S. P. y WATANUKI, J. (1975) The Crisis of Democracy: On the Governability of Democracies, EUA: New York University Press.

GERIG, M. (2018) «Interpretar el acontecimiento, transformar la vida: de la falta de urgencia al comunismo hermenéutico», ISEGORÍA. Revista de Filosofía Moral y Política, N. ${ }^{\circ}$ 58, enero-junio, pp. 255-270. https://doi.org/10.3989/ Isegoria.2018.058.14

HARVEY, D. (2004) El nuevo imperialismo, Madrid: Akal.

HARVEY, D. (2007) Breve historia del neoliberalismo, Madrid: Akal.

HAYEK, F. A., (1996), «Los Principios de un orden social liberal», Revista Estudios Públicos, No 6. Santiago de Chile. pp. 179-180.

HUNG Ho-fung (2010) «China, ¿la criada de Estados Unidos? El dilema de la RPCh en la crisis global», New Left Review, 60 (enero-febrero 2010), pp. 5-24. https:// newleftreview.es/issues/60/articles/ho-fung-hung-china-la-criada-de-estadosunidos.pdf

LACLAU, E. (2005) La razón populista, Buenos Aires: Fondo de Cultura Económica. LYOTARD, J. F. (1987) La condición posmoderna. Informe sobre el saber, Barcelona: Ediciones Cátedra.

LUXEMBURGO, R. (1967) La acumulación de capital, México: Editorial Grijalbo.

MIROWSKI P. y PLEHWE, D. (Eds.) (2009) The road from Mont Pèlerin. The making of the neoliberal thought collective, Cambridge (Massachusetts): Harvard University Press.

PANITCH, L. y GINDIN, S. (2005) «El liderazgo del capital global», New Left Review, 35, (sep/oct 2005), pp. 47-68. https://newleftreview.org/article/download_ pdf $?$ language $=$ es\&id $=2583$

PANITCH, L. y GINDIN, S. (2015) La construcción del capitalismo global: la economía política del imperio estadounidense, Madrid: Akal.

SCHMITT, C. (1985) Teoría del partisano. Notas complementarias al concepto de lo político, México: Folio Ediciones.

SCHUMPETER, J. A. (1968) Capitalismo, socialismo y democracia, Barcelona: Orbis. STRAUSS, L. (2007) Liberalismo antiguo y moderno, Buenos Aires: Katz.

VATTIMO, G. y ZABALA, S. (2012), Comunismo hermenéutico. De Heidegger a Marx, Barcelona: Herder.

WADE, R. (2006), «Asfixiar el Sur», New Left Review, 38. (may-jun 2006), pp. 101113. https://newleftreview.es/issues/38/articles/robert-wade-asfixiar-al-sur.pdf 
WALLERSTEIN, I. (1996) Después del liberalismo, México: Siglo XXI editores/ CIICH-UNAM.

WALLERSTEIN, I. (1998) Impensar las Ciencias Sociales. Los límites de los paradigmas decimonónicos, México: Siglo XXI editores/CIICH-UNAM.

WALLERSTEIN, I. (2004), Capitalismo histórico y movimientos antisistémicos, Akal: Madrid.

WALLERSTEIN, I. (2005) La Decadencia del Poder Estadounidense, México: Era.

WALLERSTEIN, I. (2007) Geopolítica y geocultura. Ensayos sobre el moderno sistema mundial, Barcelona: Editorial Kairós.

WALLERSTEIN, I. (2014) El moderno sistema mundial. Vol. IV: El triunfo del liberalismo centrista, 1789-1914, México: Siglo XXI editores.

ŽIŽEK S. (2011) En defensa de causas perdidas, Madrid: Akal.

ŽIŽEK, S. (2006) Visión de paralaje, Buenos Aires: Fondo de Cultura Económica. 